\title{
Chain mobility in polymer systems : on the borderline between solid and melt 1. Lamellar doubling during annealing of polyethylene
}

Citation for published version (APA):

Rastogi, S., Spoelstra, A. B., Goossens, J. G. P., \& Lemstra, P. J. (1997). Chain mobility in polymer systems : on the borderline between solid and melt 1. Lamellar doubling during annealing of polyethylene. Macromolecules, 30(25), 7880-7889. https://doi.org/10.1021/ma970519o

DOI:

$10.1021 /$ ma970519o

Document status and date:

Published: 01/01/1997

Document Version:

Publisher's PDF, also known as Version of Record (includes final page, issue and volume numbers)

Please check the document version of this publication:

- A submitted manuscript is the version of the article upon submission and before peer-review. There can be important differences between the submitted version and the official published version of record. People interested in the research are advised to contact the author for the final version of the publication, or visit the $\mathrm{DOI}$ to the publisher's website.

- The final author version and the galley proof are versions of the publication after peer review.

- The final published version features the final layout of the paper including the volume, issue and page numbers.

Link to publication

\footnotetext{
General rights

- You may freely distribute the URL identifying the publication in the public portal. follow below link for the End User Agreement:

www.tue.nl/taverne

Take down policy

If you believe that this document breaches copyright please contact us at:

openaccess@tue.nl

providing details and we will investigate your claim.
}

Copyright and moral rights for the publications made accessible in the public portal are retained by the authors and/or other copyright owners and it is a condition of accessing publications that users recognise and abide by the legal requirements associated with these rights.

- Users may download and print one copy of any publication from the public portal for the purpose of private study or research.

- You may not further distribute the material or use it for any profit-making activity or commercial gain

If the publication is distributed under the terms of Article $25 \mathrm{fa}$ of the Dutch Copyright Act, indicated by the "Taverne" license above, please 


\title{
Chain Mobility in Polymer Systems: on the Borderline between Solid and Melt. 1. Lamellar Doubling during Annealing of Polyethylene
}

\section{S. Rastogi,* A. B. Spoelstra, J . G. P. Goossens, and P. J . Lemstra}

Eindhoven Polymer Laboratories/ The Dutch Polymer Institute (DPI), Department of Chemical Engineering, Eindhoven University of Technology, P.O. Box 513, 5600 MB Eindhoven, The Netherlands

Received April 16, 1997; Revised Manuscript Received September 18, $1997^{\otimes}$

\begin{abstract}
In-situ small-angle X-ray scattering (SAXS) and low-frequency Raman spectroscopy experiments have been performed to study the mobility and motion of polymer chains upon annealing in a temperature range d ose to but bel ow the melting temperature. Ultrahigh molecular weight polyethylene, UHMW-PE, was taken as the model polymer, which was crystallized from solution. Regularly stacked lamellar crystals could be obtained after drying the solution-crystallized films. SAXS studies revealed that, upon heating above $110^{\circ} \mathrm{C}$, the lamellar thickness (long period) increases to twice the initial value. This quantum increase was confirmed by transmission electron microscopy (TE M). By means of in-situ low-frequency Raman spectroscopy it was observed that during heating a shift occurs in the longitudinal acoustic (LA) Raman frequency to lower values, indicative of an increase in the thickness of the crystalline core. The combined experimental observations indicate that thickening occurs via a mutual chain rearrangement between the adjacent lamellae involving a sliding motion along the chain axis to a doubling of the lamellar thickness. A model to explain the quantum increase, i.e., doubling, is proposed.
\end{abstract}

\section{Introduction}

The motion of chains in quiescent polymer melts is confined to a reptative diffusion along the contour length, as proposed by De Gennes..$^{1,2}$ In the constitutive equations based on the concept of chain reptation, it is assumed that the longest relaxation times in polymer melts correspond to the reptative motion of complete chains. $^{3}$ In the case of ultrahigh molecular weight polyethylene, UHMW-PE, possessing a weight average molar mass $M_{w}$ over $10^{6} \mathrm{~g} \cdot \mathrm{mol}^{-1}$, the experimentally determined ${ }^{4,5}$ longest relaxation times exceed $10^{4} \mathrm{~s}$ derived from the stress relaxation modulus $\mathrm{G}(\mathrm{t})$ as a function of time at $180{ }^{\circ} \mathrm{C}$.

Processing of UHMW-PE via conventional routes is virtually impossible due to the high mol ar mass and the excessive high melt viscosity. The viscosity of polymer melts, above a certain threshold value for the molar mass $M_{c}$, is given by $\log \eta_{0}=C+3.4 \log M_{w}$, where $\eta_{0}$ is the zero-shear viscosity. The strong increase in the melt viscosity with increasing molar mass is related to entanglement coupling ${ }^{6}$ and the presence of a physical entanglement network that can be characterized by an average molecular weight, $\left\langle\mathrm{M}_{\mathrm{e}}\right\rangle$, between the physical cross-links.

Despite many efforts in the past, no advantage could be gained by processing disentangled solution-crystallized UHMW-PE via the melt. We anticipated an initial lower melt viscosity upon heating disentangled UHMWPE above the melting temperature in view of the fact that a certain time period is needed to form an equilibrium melt starting from (completely) disentangled systems. The long chains in UHMW-PE have to reptate into each other and the tube renewal time, especially for the high molar mass tail, is expected to be relatively long, on the order of a few hours. ${ }^{5}$

The experimental observation that no memory effect could be found with respect to the crystallization history

\footnotetext{
* To whom correspondence should be addressed.
${ }^{\otimes}$ Abstract published in Advance ACS Abstracts, November 15, 1997.
}

upon heating disentangled UHMW-PE above the melting temperature and, moreover, the complete loss of (ultra)drawability upon recrystallization 7,8 from the melt prompted us to study in detail the "fate" of a polymer molecule on the borderline between (disentangled) solid and melt. An additional stimulus to study the motion and mobility of chains upon annealing and melting was the observation by Barham and Sadler that folded-chain pol yethylene crystals "explode" upon melting. $^{8}$ In solution-crystallized polyethylene, the folded chains possess a rather compact nonequilibrium conformation, and upon melting, the chains immediately adopt a random-coil conformation. This effect of "chain explosion" and, consequently, a fast interpenetration of chains upon mel ting is due to the entropic driving force. This was explored by us to promote wel ding and fusion during processing of UHMW-PE and other crystalline polymers, as will be discussed in a subsequent paper. ${ }^{9}$

In this paper, we present a detailed study concerning chain mobility during annealing in a temperature range close to but below the melting point of solution-crystallized UHMW-PE. By proper crystallization from semidilute solutions of UHMW-PE, we could make films possessing well-stacked lamellar crystals. Heating these films showed that the SAXS long period shows a quantum jump and the lamellar crystal doubles its thickness. By combining small-angle X-ray scattering (SAXS), transmission electron microscopy (TEM) and low-frequency Raman spectroscopy we could trace the confined motion of the polymer chains along its chain axis. Low-frequency Raman spectroscopy has been used to obtain detailed information concerning the chain reorganization during annealing in analogy with the work of Kim and Krimm on poly(ethylene oxide). ${ }^{10}$

\section{Experimental Section}

A. Materials and Film Preparation. Solution-crystallized films were obtained by dissolving UHMW-PE $\left(\mathrm{M}_{\mathrm{w}} \sim 3 \times\right.$

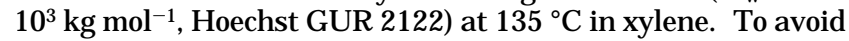
air bubbles in the film, the solvent was degassed and flushed with nitrogen gas to prevent oxidation. The polymer concentration was $1 \%$ by weight. After dissolution, the hot solution 
was quickly transferred to an aluminum tray and left to cool slowly under quiescent conditions. Upon cooling, a gel is formed and the wet gel is stapled onto a cardboard to prevent lateral shrinkage. The gel is left to dry. This process took about 1 week, and we anticipate no xylene is left in the dried gel. The dry film thus formed was subjected to the experimental investigations. A part of the wet gel, as obtained just after cooling to room temperature, was transferred to Lindemann capillaries, which were sealed to avoid any evaporation of the solvent during heating and cooling, to investigate the morphology in the gel by in-situ simultaneous small-angle (SAXS) and wide-angle X-ray (WAXS) measurements.

B. Characterization Techniques. B.1. Simultaneous Small-Angle and Wide-Angle X-ray Scattering (SAXS/ WAXS). The SAXS/WAXS studies were performed at station 8.2 of the synchrotron radiation facility available in Daresbury, U.K.11 The WAXS data were collected with a curved Inel detector positioned such that its center of curvature coincided with the sample position. The SAXS patterns were collected on a multiwire quadrant detector positioned at $3.5 \mathrm{~m}$ from the sample. The SAXS and WAXS data were accumulated simultaneously in time frames of $36 \mathrm{~s}$ for the solutions, whereas time frames of $6 \mathrm{~s}$ were used for the films. A Linkam THMS 600 hot-stage mounted on the optical bench with a sample holder (capillary/film) was used to perform heating, cooling, or annealing experiments. The silver heating block of the hot stage contained a $4 \times 1 \mathrm{~mm}^{2}$ conical hole, allowing the X-rays to pass through. In the sample holder, a J -type thermocouple was fitted to measure the sample temperature. For calibration of the SAXS detector, the diffraction pattern from an oriented specimen of wet collagen was used. A polyethylene single crystal mat was used to calibrate the WAXS detector. A parallel plate ionization detector was placed before and after the sample to record the incident and transmitted intensity. The experimental data were normalized for the transmitted intensity and corrected for detector response and the background scattering, i.e., subtraction of the scattering from the camera and the hot stage.

B.2. Raman Spectroscopy. Raman spectra were obtained in situ either during heating or cooling, using a Dilor $X Y$ triple monochromator spectrometer. Laser excitation was provided by a Spectra Physics argon ion laser set to provide a power of $100 \mathrm{~mW}$ at the sample. Since the longitudinal acoustic (LA) modes appear close to the excitation line of the primary beam, special care was taken to suppress the intensity due to the background, which tends to distort the bands close to the primary beam. In order to minimize this error, it is desirable to obtain well-resolved peaks, since subtraction of the background has only a small effect on the peak frequencies. This was achieved using small slit widths of typically $0.5 \mathrm{~cm}^{-1}$ in order to record spectra close to $5 \mathrm{~cm}^{-1}$. The optics were optimized such that the signal to noise ratio was better than 50:1. On this basis, we were able to locate strong LA mode peaks with a resolution better than $0.5 \mathrm{~cm}^{-1}$. During the heating and cooling scans, spectra were collected in time frames of $12 \mathrm{~s}$. The frequency shift of a peak with respect to the excitation line, denoted by $\Delta v$, expressed in $\mathrm{cm}^{-1}$ throughout the text, can be converted into values for the crystalline core using the relationship derived by Schaufele and Schimanouchi ${ }^{12}$ for paraffins, and used by others in the past on polyethylene:

$$
\Delta v=(\mathrm{m} / 2 \mathrm{Lc})(\mathrm{E} / \rho)^{1 / 2}
$$

where $\Delta v$ is the shift in vibrational frequency of the LA mode expressed in $\mathrm{cm}^{-1}, \mathrm{~m}$ is the order of the vibrational mode, $\mathrm{L}$ is the length of the vibration chain, c is the vel ocity of light, $E$ is Young's modulus, and $\rho$ is the density. Using the known values of $\rho, \mathrm{L}$, and $\Delta v$ from the Raman spectrum, the value of Young's modulus of PE was determined to be $3.6 \times 10^{12}$ dynes/ $\mathrm{cm}^{2}$. A Raman chain length, $L_{R}$, can then directly be calculated from the first order by using the expression $L_{R}=3169 / \Delta v$. $A$ rigorous treatment for polyethylene would require special features associated to chain branches and fold surfaces. These effects are known to be small, but their precise values, on which a quantitative comparison with other techniques like SAXS and electron microscopy could be made, are yet unknown.

B.3. Transmission Electron Microscopy (TEM). The morphology of the unannealed and annealed solution-crystallized films was examined using a J EOL 2000FX transmission electron microscope operating at $80 \mathrm{kV}$. For TEM, the films were trimmed at $-140{ }^{\circ} \mathrm{C}$ and subsequently stained in a ruthenium tetraoxide solution for $16 \mathrm{~h}$ at $25{ }^{\circ} \mathrm{C}$ for the enhancement of contrast between the amorphous and crystalline regions and for morphology fixation. ${ }^{13}$ Finally, thin sections with a thickness of $70 \mathrm{~nm}$ were obtained at room temperature using a Reichert Ultracut E microtome.

C. Experimental Limitations. Since we used three different techniques to examine different properties of the material, i.e., SAXS, low-frequency Raman spectroscopy, and electron microscopy (TEM), a suitable interpretation of the results can only be made by taking into account the scope and limitations of the techniques. The difference in electron density between crystalline lamellae and the disordered interlamellar material is detected directly by SAXS, but a prerequisite for the appearance of a discrete maximum is a regular stacking of lamellae of reasonably uniform size. The position of the peak then indicates the average repeat distance in the stacks of lamellae. In order to evaluate the dimensions of the crystalline core and the amorphous zone in the material, a few assumptions need to be made and a model is required; the most commonly used model is the two-phase model, which has its limitations. ${ }^{14}$

The contrast in the electron microscope is also a result of electron density variations. Since this contrast is artificially enhanced by staining, it reflects the permeability variations within the material. A low permeability is associated with crystalline order and thus a high original electron density. The arrangement of lamellae can be observed directly. The accuracy in the absolute lamellar thickness determination is limited, because of possible distortion of the specimen due to staining.

The Raman active $L A$ mode depends on the average length of the extended chains within the crystal core (stems). ${ }^{15-17,19}$ The width of the peak would depend on the dispersity of the length of the extended chains. Here, the stems will be the main part of the crystalline core together with the trans content of the amorphous region in the transient zone (between the crystalline core and the amorphous region). Furthermore, chains can be tilted within the lamellae. Therefore, it cannot be a true measure of the lamellar thickness al one. ${ }^{17,18}$ Moreover, the LA mode will be independent of the stacking of Iamellae in the bulk. ${ }^{19}$

\section{Results and Discussions}

A. Structure in the Wet Gels and the Dried Solution-Crystallized Film. In order to understand the structure in solution-crystallized films, we have investigated the structure in wet gels of 1 wt \% UHMW$P E$, which is the precursor for making the films. So far, the microstructure of UHMW-PE gels has been investigated indirectly by substituting the solvent by a mixture of monomers and subsequently cross-linking. 20,21 Because of the high flux of the synchrotron source, it is possible to investigate the structure development in the gel. Heating and cooling scans were performed on the gel. Figure la is a plot of the SAXS intensity versus time versus scattering wavenumber, $q$ $=(4 \pi / \lambda) \sin \theta$, where $2 \theta$ is the scattering angle and $\lambda$ the wavelength of the X-rays, which in our case is 0.154 $\mathrm{nm}$. The melting (dissolution) temperature of the gel, $117^{\circ} \mathrm{C}$, as observed by X-rays at wide angles with the loss of 110 and 200 reflections of polyethylene is in good agreement with the value measured by optical microscopy and DSC for the 1\% UHMW-PE gel.

In the small-angle region (Figure 1a) a broad maximum is observed at low temperatures, which, on heat- 
(a)

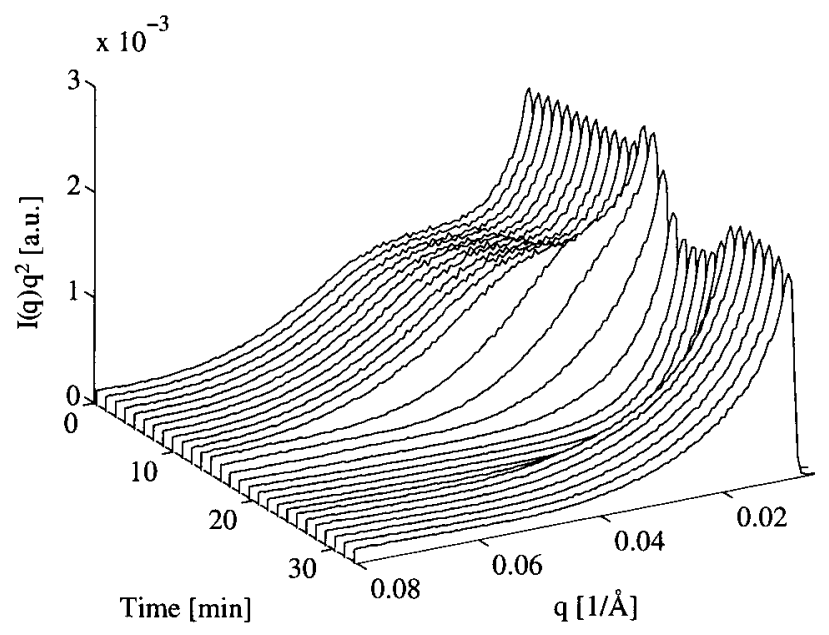

(b)

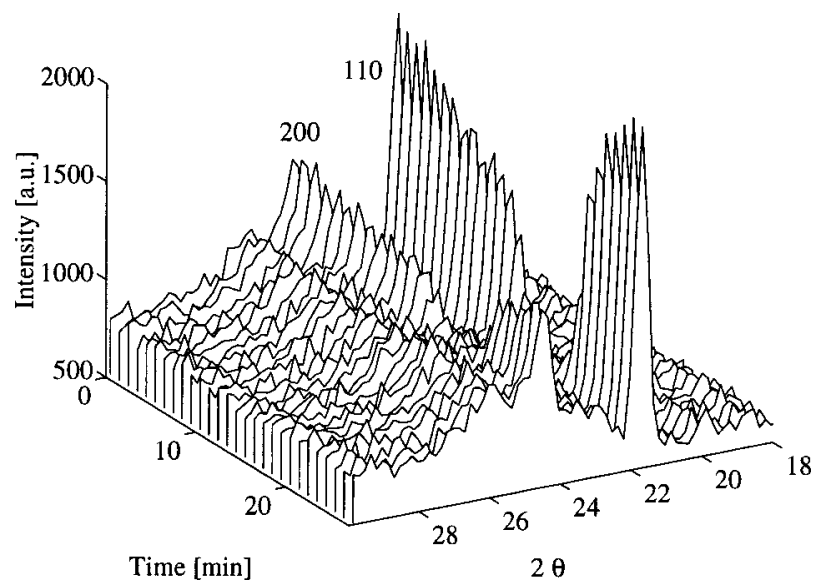

Figure 1. Time resolved X-ray data of a 1 wt \% UHMW-PE gel during a heating scan from 30 to $115^{\circ} \mathrm{C}$ at $5^{\circ} \mathrm{C} / \mathrm{min}$ (i.e., 0-17 min along the time axis) and then holding at $115^{\circ} \mathrm{C}$ for $3 \mathrm{~min}(17-20 \mathrm{~min})$ followed by a cooling scan from 115 to 50 ${ }^{\circ} \mathrm{C}$ at $5^{\circ} \mathrm{C} / \mathrm{min}(21-34 \mathrm{~min})$ : (a) 3-D plot of SAXS Lorentzcorrected intensity, I (q) $q^{2}$, versus scattering wavenumber, $q$, ranging from $0.01<q<0.08 \AA^{-1}$, versus time; (b) 3-D plot of WAXS intensity versus scattering angle, $2 \theta$, ranging from 18 $<2 \theta<30^{\circ}$, versus time.

ing, disappears at $117{ }^{\circ} \mathrm{C}$. This maximum should correspond to the averaged periodic electron density fluctuations in the solution corresponding to the average distance between crystalline domains present within the gels. A schematic representation of such semicrystalline gels ${ }^{22}$ is shown in Figure 2. The crystalline domains, represented by folded-chain crystals, are connected to each other by amorphous material, i.e., connecting chains, where the solvent, not depicted in Figure 2, is interlocked. The relatively strong intensity, though surprising at first instance, is a result of the high electron density difference between the crystalline domains of the gel and the amorphous part immersed in the solvent xylene. Simultaneously, with the disappearance of the maximum in the small-angle region, the 110 and 200 diffraction peaks of the orthorhombic packing of the PE-chains disappear at the wide angles (see Figure 1b). The high background below the sharp diffraction peaks of crystalline polyethylene (F igure 1b) originates from the solvent and the amorphous part in the gel. Because of the relatively poor signal to noise ratio, the higher order reflections of polyethylene at the

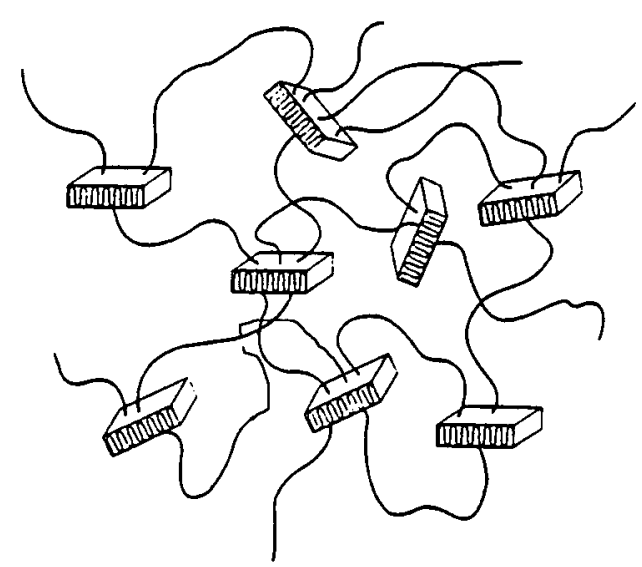

Figure 2. Schematic representation of a semicrystalline polymer gel. ${ }^{22}$

higher Bragg angles could not be detected. On cooling from solution, a maximum in the small-angle region reappears, although the intensity is much lower. However, the maximum becomes more distinct when the sample is left to anneal for a long time at room temperature. Concurrently, the reflections of the orthorhombic unit cell reappear at the wide angles.

When the solvent is evaporated slowly in the constrained film, the gravitational forces will lead to the regular stacking of lamellae in the solvent free film. ${ }^{23}$ Since the crystals are formed from solution, regular chain folding may be anticipated in the crystalline domains of the solution-crystallized film. Because of the regular stacking, sharp reflections satisfying the Bragg condition $2 \mathrm{~d} \sin \theta=\mathrm{n} \lambda$ for the first, second, and third order for an average lamellar thickness of $12 \mathrm{~nm}$ may be observed. Figure $3 a$ shows such a small-angle pattern when the sample is viewed edge-on. The sharp peaks are indicative of the monodispersity of the lamellar thickness of $12 \mathrm{~nm}$. The orientation in the stacking of crystals is self-evident from WAXS when the sample is viewed edge-on (Figure $3 b$ ). No orientation is observed when the sample is viewed through the plane.

The regular stacking of crystals as shown in Figure $3 a$ in the gel film is confirmed by TEM. Figure $3 c$ shows a regular stacking of lamellae of the order of $12 \mathrm{~nm}$ as viewed edge-on along the thickness direction of the sample. The chain direction is perpendicular to the thickness direction of the lamellae. The bright regions are from the crystalline core of the material, whereas the dark regions correspond to the amorphous part. Twisting of the lamellae along the crystal length may also be observed, which is due to screw dislocations.

Raman spectra for the LA mode of the solutioncrystallized film as viewed edge-on are depicted in Figure 3d. Our observations show the presence of a strong maximum at the frequency $26.7 \mathrm{~cm}^{-1}$. With the Schaufele and Schimanouchi model, ${ }^{12}$ the first-order LA mode frequency $26.7 \mathrm{~cm}^{-1}$ corresponds to the straight chain length of $11.9 \mathrm{~nm}$. Surprisingly, this value is very close to the lamellar thickness $L_{x}$ as measured by SAXS. Several explanations, as will be discussed below, can be provided, which may lead to such a good agreement.

Considering the homogeneous elastic rod model in which the LA mode is a measure of the straight stems present in the crystalline core and with decoupling at the first gauche sequence in the fold, these results suggest that little space is left for the amorphous content of the material. Such a hypothesis supports the view of tight folds at the crystal surface. An al ternative 

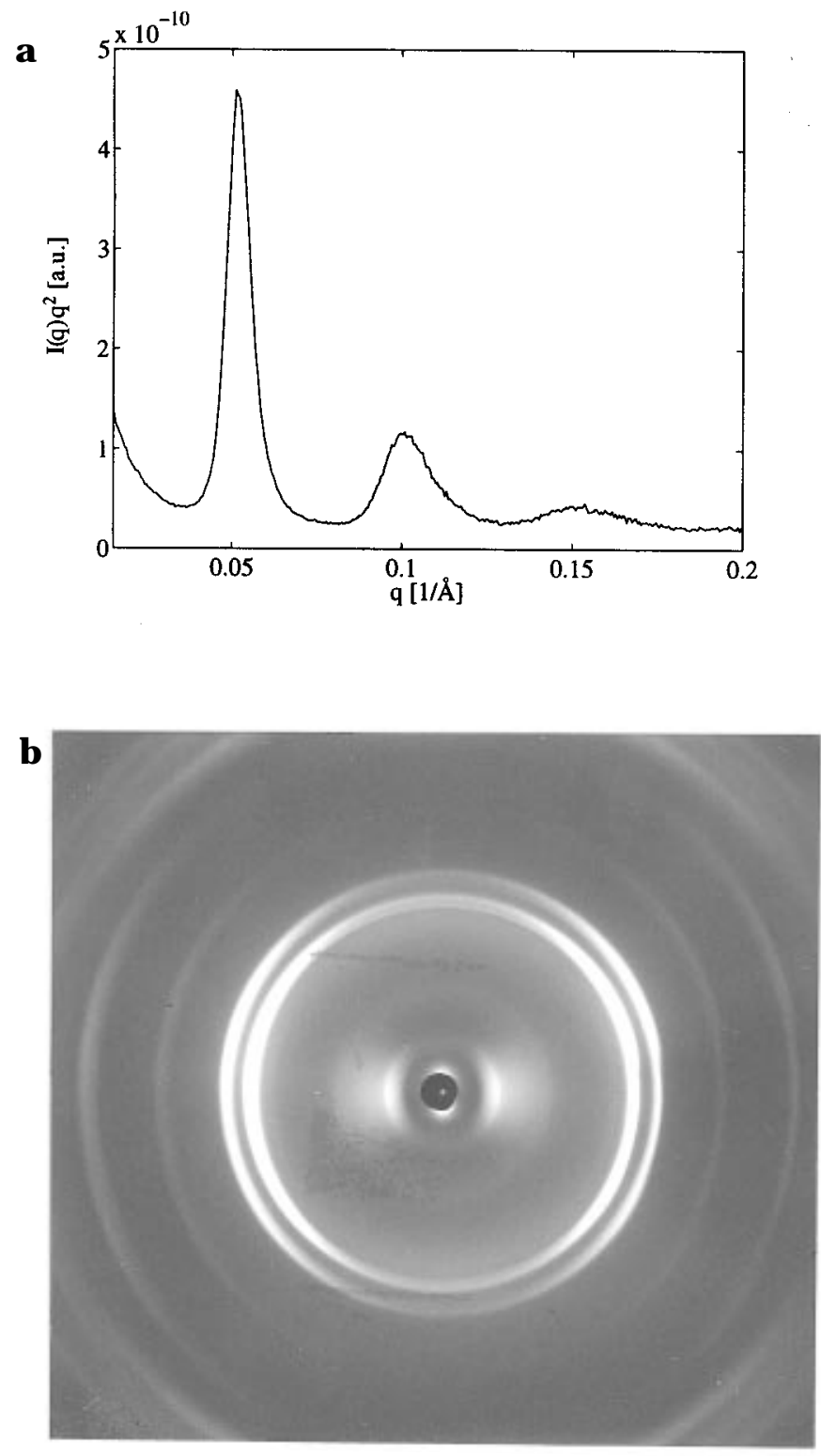

Figure 3. Structure of a solution-crystallized UHMW-PE film edge-on; (c) transmission electron micrograph, viewed edge-on;

explanation for the same effect can be that the fold surface does perturb the LA mode. The net result of such perturbations is that the LA mode frequency is identical to the $L_{x}$. This can be explained in several ways. Peticolas and co-workers introduced the concept of the composite rod vibration to explain the effect of perturbations on the LA mode frequency due to folds. ${ }^{24}$ In this model, the homogeneous crystalline rod, envisaged originally for paraffins, is replaced by a rod composed of a crystalline core bounded by amorphous ends. Then, the vibrational frequency of the LA mode depends on the relative magnitudes of Young's moduli of the crystalline and amorphous phases. Since a lower value of the modulus was ascribed to the ends of the rod than to the core, this leads to a lower LA mode frequency compared to that of a fully crystalline rod of the same length. This results in an overestimation of the true value of the crystalline core, raising the possibility that the experimental LA mode frequency, as we determined, comprises the length of the crystalline core together with a small portion of gauche content from the amorphous zone. Strobl and $\mathrm{Eckel}^{25}$ and $\mathrm{Hsu}$ and $\mathrm{Krimm}^{26}$ made further refinements by taking into
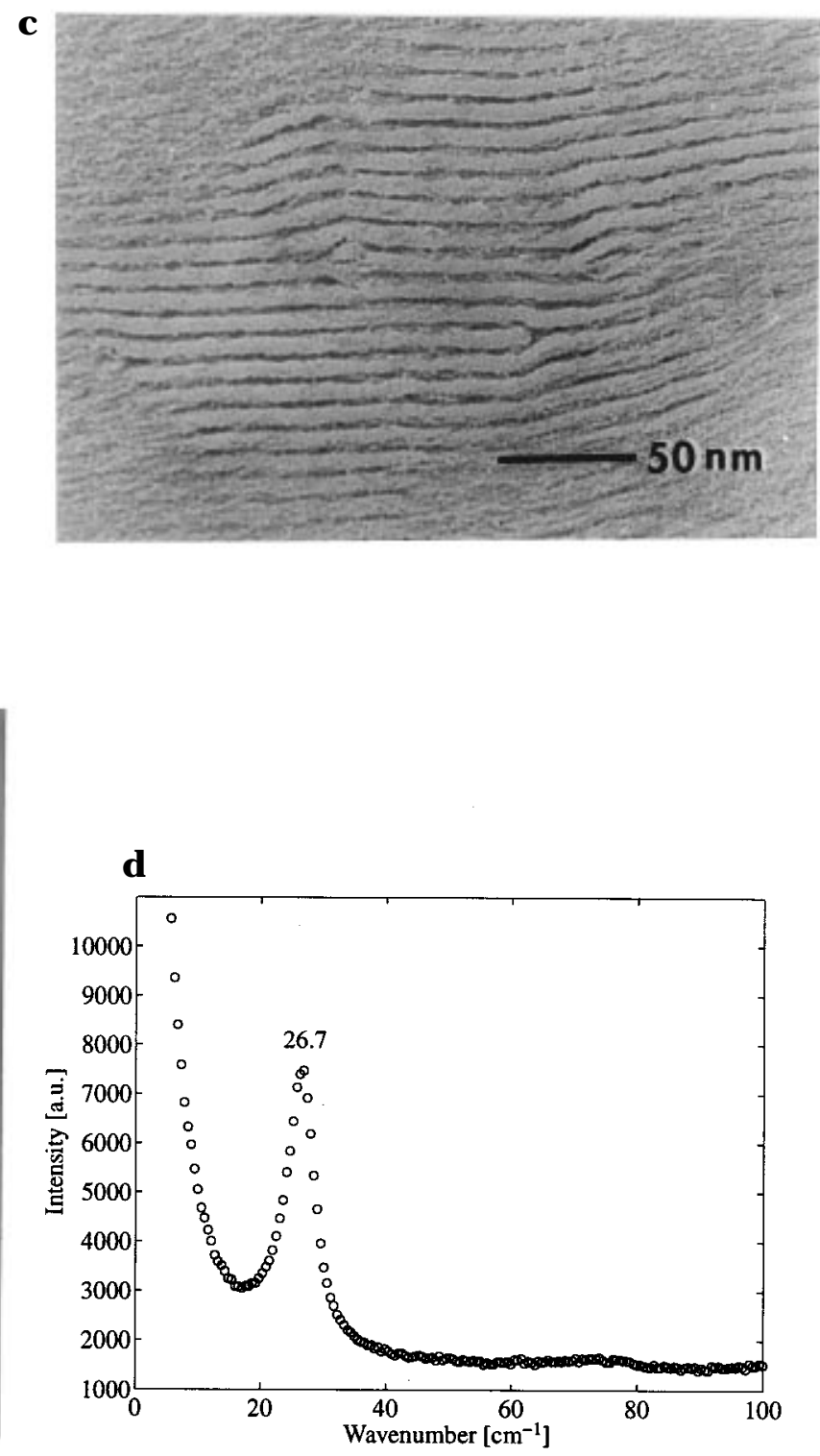

(a) SAXS pattern, viewed edge-on; (b) WAXS pattern, viewed (d) low-frequency Raman spectrum, viewed edge-on.

account forces and masses acting on the ends of the rod to simulate the effects of the interlamel lar interactions and fold surface damping, respectively. Whereas a mass perturbation decreases the theoretical LA mode frequency and is hence in the same direction as the effect of a lower modulus of the surface layer, the inclusion of an interlamellar force results in an increase in the frequency. The theoretical estimation of the LA mode frequency depends upon the precise values of these perturbations and is beyond the scope of this paper. Furthermore, to our knowledge, no general agreement exists on the estimation of the perturbation values.

We would like to emphasise at this point that our observations on $L_{R}$, which are in good agreement with $L_{x}$, demonstrate that the effect of perturbations in the determination of the LA mode frequencies could not be ignored in the solution-crystallized UHMW-PE films. The agreement between the results obtained from Raman and SAXS suggests further that folds due to the re-entry of chains are rather tight, as normally anticipated in solution-crystallized films. The sharpness of the LA mode frequency peak in Figure $3 d$ with a relatively low background at the low frequencies points 


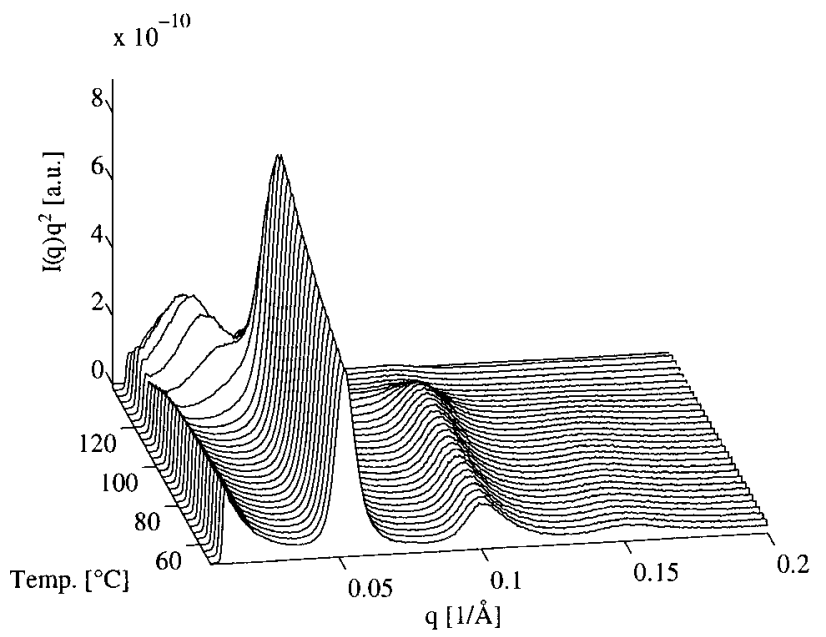

Figure 4. SAXS patterns of the solution-crystallized UHMWPE film during a heating scan from 25 to $140^{\circ} \mathrm{C}$ at $10^{\circ} \mathrm{C} / \mathrm{min}$.

to the monodispersity in the rod length of the crystalline core along with the low fraction of amorphous material associated with the crystal surface.

B. Chain Mobility below the Melting Temperature: Lamellar Doubling. SAXS Observations. We have investigated the chain mobility during heating in a regularly stacked solution-crystallized UHMW-PE film. Figure 4 shows the timeresolved small-angle X-ray scattering patterns while heating at the rate of $10^{\circ} \mathrm{C} / \mathrm{min}$. At low temperatures, the SAXS patterns show three peaks with decreasing intensity along the scattering wavenumber $q$, satisfying the Bragg condition for the first $\left(q=0.052 \AA^{-1}\right)$, second $\left(q=0.104 \AA^{-1}\right)$, and third ( $\left.q=0.156 \AA^{-1}\right)$ order of an average lamellar thickness of $12 \mathrm{~nm}$. On heating above the threshold temperature of $110^{\circ} \mathrm{C}$, initially a broad weak peak at q $=0.0262 \AA^{-1}(\mathrm{~d}=24 \mathrm{~nm})$ appears, which becomes sharper and more intense, with diminishing intensities of the second and third orders of the $12 \mathrm{~nm}$ crystals and a simultaneous decrease in intensity of the first order for the $12 \mathrm{~nm}$ crystals. The increase in lamellar thickness corresponds to a major rearrangement of chains with thickening. It is evident that the majority of the lamellar crystals increase their thickness to twice the initial value. Such a quantum increase in thickening is rather surprising and would require a proper register of lamellae with the same thickness. During heating, the loss in long range order is observed by a loss of the peaks for the second and third order. Simultaneously, the appearance of a comparatively broad peak, corresponding to a lamellar thickness of 24 $\mathrm{nm}$, indicates that after the quantum increase in lamellar thickness, the lamellae are no longer in a perfect register, as observed before heating. Moreover, it is intriguing to observe that, after doubling, lamellae melt without substantial further thickening. Figure 5 shows a schematic representation of the increase in Iamellar thickness with temperature. To quote the numbers, the lamellar thickness first shows a quantum increase from 12 to $24 \mathrm{~nm}$, followed by further thickening to a maximum value of $27 \mathrm{~nm}$ before melting. Lamellae start to thicken to double the initial value above point $\mathrm{B}, 110^{\circ} \mathrm{C}$. Figure 5 may be divided into three different regions, $A B, B C$, and $C D$. Within region $A B$, the lamellar thickness is constant, whereas in region $B C$ (shown by the dotted line), two different populations in terms of lamellar thicknesses, i.e., 12 and 24 nm, exist. $C D$ is the region where the logarithmic increase in lamellar thickness occurs during annealing or heating.

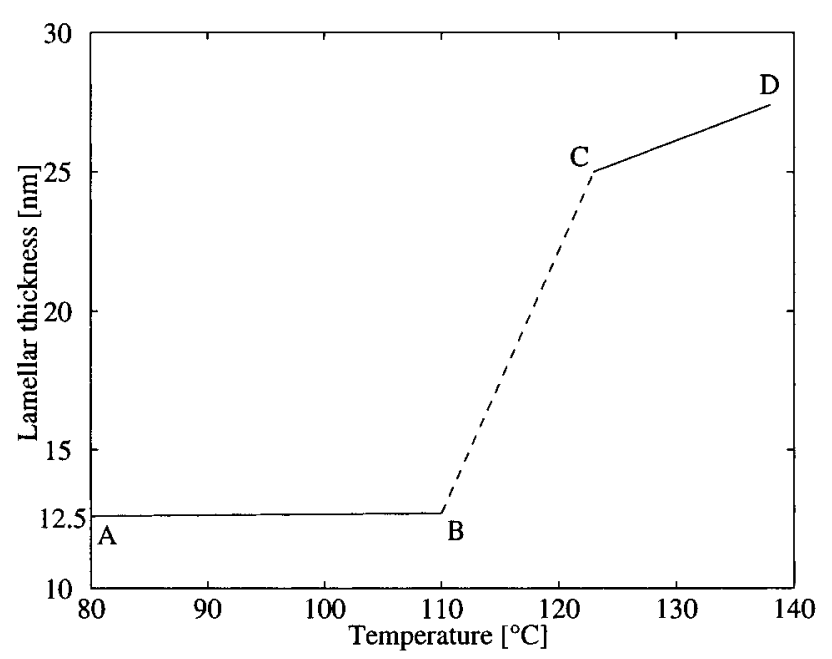

Figure 5. Schematic representation of the increase in the lamellar thickness as a function of temperature.

Regi on BC in Figure 5, which lies between 110 and 123 ${ }^{\circ} \mathrm{C}$, is of significance to evaluate the mechanism involved in lamellar thickening. Therefore, it is of interest to investigate the influence of annealing within this region. A heating scan of the sample from 75 to $115^{\circ} \mathrm{C}$ at the rate of $5{ }^{\circ} \mathrm{C} / \mathrm{min}$ is shown in Figure $6 \mathrm{a}$. Above $110{ }^{\circ} \mathrm{C}$, a few lamellae in the bulk thicken to double the initial value, while the remaining crystals do not change in terms of thickness. Thus, in the bulk of the sample, two distinct populations of lamellar thicknesses exist. When the sample is left to anneal at $115^{\circ} \mathrm{C}$, the peak intensity for the $12 \mathrm{~nm}$ crystals decreases, while a simultaneous increase in the peak intensity for the 24 $\mathrm{nm}$ crystals occurs. When the sample is heated further beyond the annealing temperature at a rate of $1^{\circ} \mathrm{C} / \mathrm{min}$, an increase in the peak intensity for $24 \mathrm{~nm}$ lamellar thickness occurs with the disappearance of the peak for the $12 \mathrm{~nm}$ lamellar thickness (see Figure 6c). The lamellae melt at approximately $135^{\circ} \mathrm{C}$ without substantial thickening beyond $24 \mathrm{~nm}$. These results clearly demonstrate that within region $\mathrm{BC}$ of Figure 5 only two distinct populations of the crystals exist, favoring the quantized thickening in the regularly stacked lamellae.

Transmission Electron Microscopy. The quantum increase in lamellar thickness is confirmed by TEM (Figure 7). The sample used for TEM was prepared by heating the solution-crystallized film to $125^{\circ} \mathrm{C}$ and annealing for $15 \mathrm{~min}$. The average lamellar thickness as measured in Figure 6 is twice the value measured in Figure 3c. The bright region in Figure 7, corresponding to the crystalline core, increased to approximately twice the value shown in Figure 3c. Further, it is noticed that the initial regular stacking of lamellae is lost in the anneal ed sample. This is in accordance with the broadening of SAXS peak and loss of the higher orders (see Figure 4).

LA Raman Spectroscopy. From the in-situ SAXS patterns alone, it is clear that the lamellar thickness increases to twice the initial value on heating, but no conclusion on the mechanism involved during thickening could be made. It may occur either via interchain diffusion between the neighboring crystals ${ }^{27}$ or via an increase in the amount of amorphous material in between the crystalline core 28 (i.e., premelting of selective small lamellae within the lamellar stacks or surface melting of the crystals) or via a melting and recrystallization process. ${ }^{29}$ All these mechanisms would lead to development of the small-angle X-ray pattern as ob- 


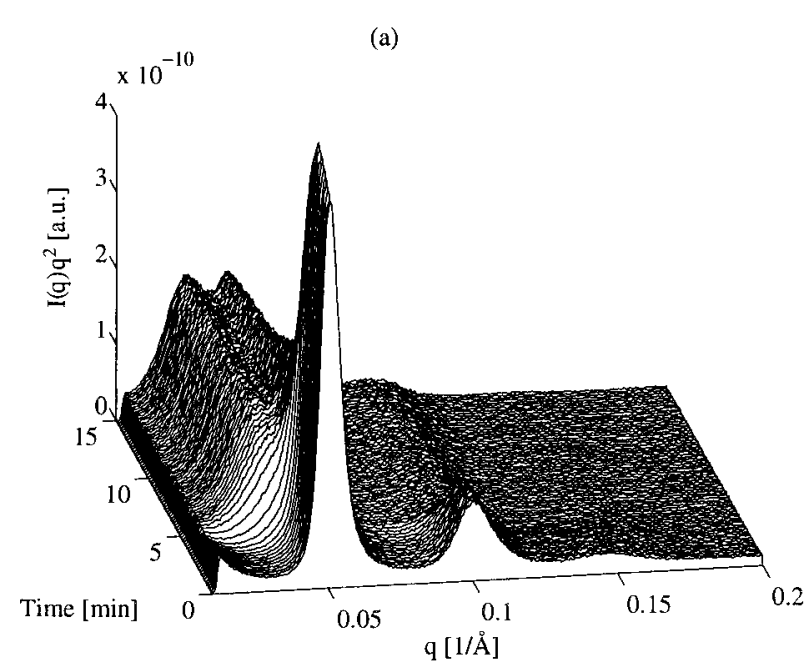

(b)

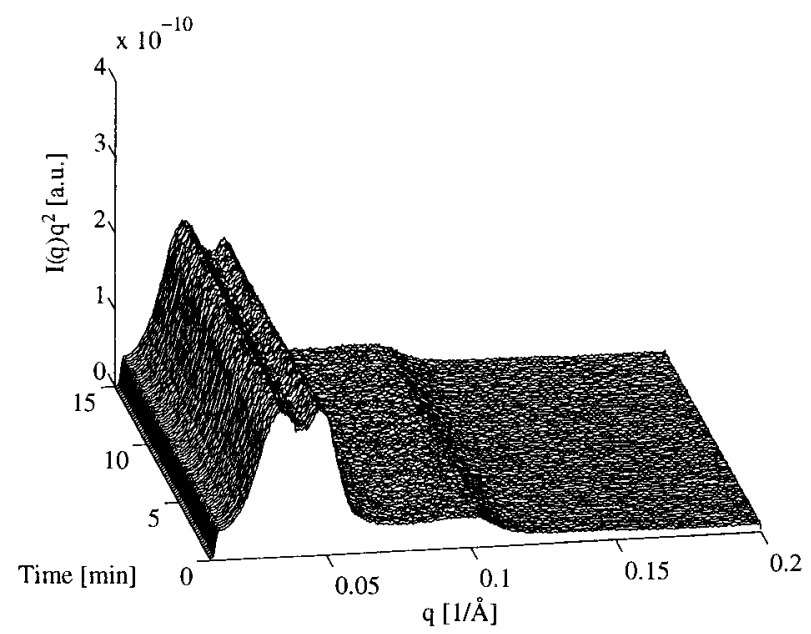

(c)

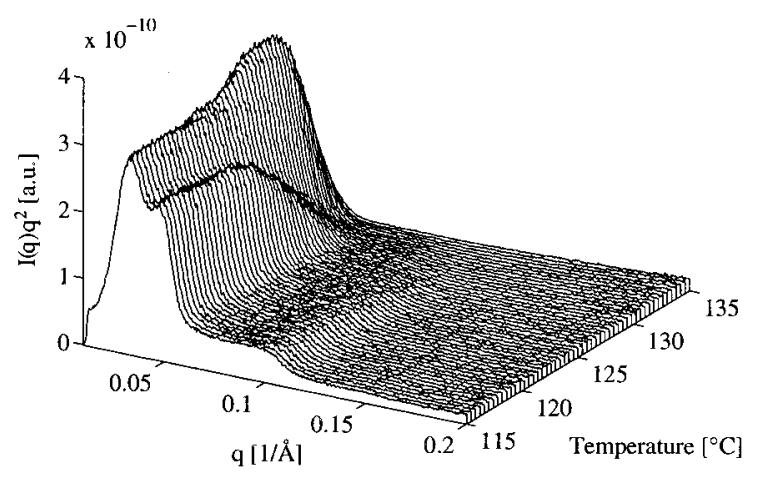

Figure 6. Time-resolved SAXS patterns: (a) obtained during a heating scan from 75 to $115^{\circ} \mathrm{C}$ at $5^{\circ} \mathrm{C} / \mathrm{min}(0-8 \mathrm{~min})$ and left to anneal (8-15 min); (b) obtained during annealing for 15 min at $115^{\circ} \mathrm{C}$; (c) obtained during a heating scan from 115 to $135^{\circ} \mathrm{C}$ at $1{ }^{\circ} \mathrm{C} / \mathrm{min}$.

served here. From earlier X-ray studies performed at wide and small angles, it was concluded that the sudden increase in lamellar thickness, which was noticed during their experimentation, is due to melting of neighboring (or al ternate) lamellae rather than to an increase in the crystalline core. ${ }^{30}$ Certainly, it would be surprising if such a mechanism could explain the exact doubling of the lamellar thickness as observed in our case. Nevertheless, such a coincidence cannot be ruled out. Our TEM results indicate that the crystalline core increases

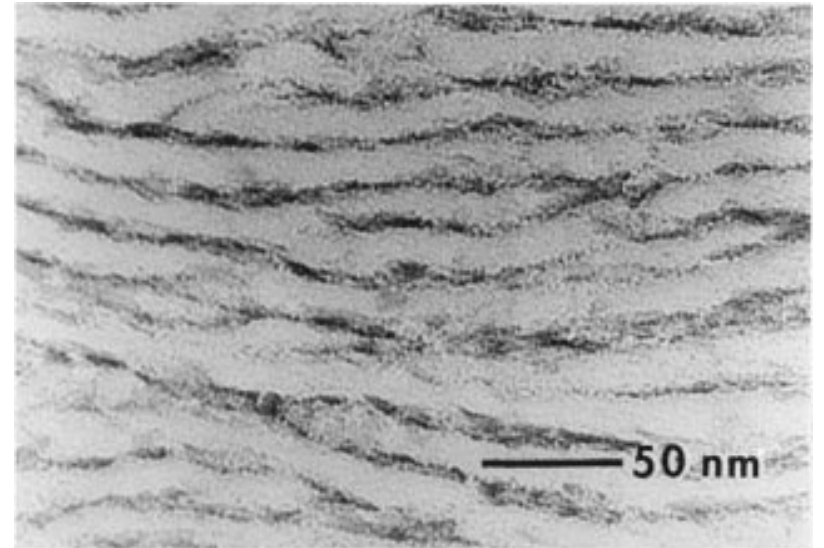

Figure 7. Transmission electron micrograph of the annealed sample showing the doubled lamellar thickness as viewed edge-on.

to a thickness of twice the initial value, indicating that melting alone of neighboring (or alternate) lamellae cannot be involved in such a dramatic increase in lamellar thickness, especially the crystalline core. However, transmission electron microscopy lacks the possibility of real time observation. To investigate the mechanism involved during chain rearrangement in the crystalline core, we performed in-situ LA Raman mode experiments at elevated temperatures. Before application of this technique for our experimentation, it is important to investigate the influence of temperature on the LA Raman mode in general.

Temperature Influence on LA Raman Mode. So far, there has not been much effort to use the LA Raman mode as a tool to reveal chain arrangement in detail at temperatures higher than room temperature. Because of the low frequencies involved in the LA Raman mode, the band shape will be affected by both the temperature and the frequency at which the experiments are performed. Very recently, crystallization and structural transitions at isothermal crystallization conditions above room temperature were followed in sharp fractionated poly(ethylene oxide). ${ }^{10}$ Since in poly(ethylene oxide) the LA Raman mode peaks are sharp, the peak position changes only slightly (in the order of $0.1 \mathrm{~cm}^{-1}$ ) close to the melting temperature, where the decrease in the interchain interaction is most prominent.

Since the SAXS pattern does not show any substantial shift after annealing the solution-crystallized film before melting (Figure 6b), we made use of such an annealed film to investigate the shift involved in the LA Raman mode due to temperature. The LA Raman peak at 13.2 $\mathrm{cm}^{-1}$ as shown in Figure 8 at $25^{\circ} \mathrm{C}$, which in fact is half the value for the LA Raman peak for lamellae having a thickness of $12 \mathrm{~nm}$, corresponds to the lamellar thickness of $24 \mathrm{~nm}$. Figure 8 shows such an example, where the LA Raman mode has been recorded during heating at a rate of $5{ }^{\circ} \mathrm{C} / \mathrm{min}$. No shift in the $13.2 \mathrm{~cm}^{-1}$ band with an increase in temperature up to $135^{\circ} \mathrm{C}$ is observed, in contrast to the anticipated shift to the lower frequencies due to thermal expansion of the unit cell as discussed in the preceding paragraph. It may be noticed that on heating below the melting temperature the peak position neither shifts nor broadens. Close to the melting temperature, a drop in the intensity with an asymmetric broadening of the LA Raman peak toward higher frequencies occurs. The following three conclusions can be drawn from these results. First, no shift in the peak below the melting temperature suggests that the length of the chain segments in the 


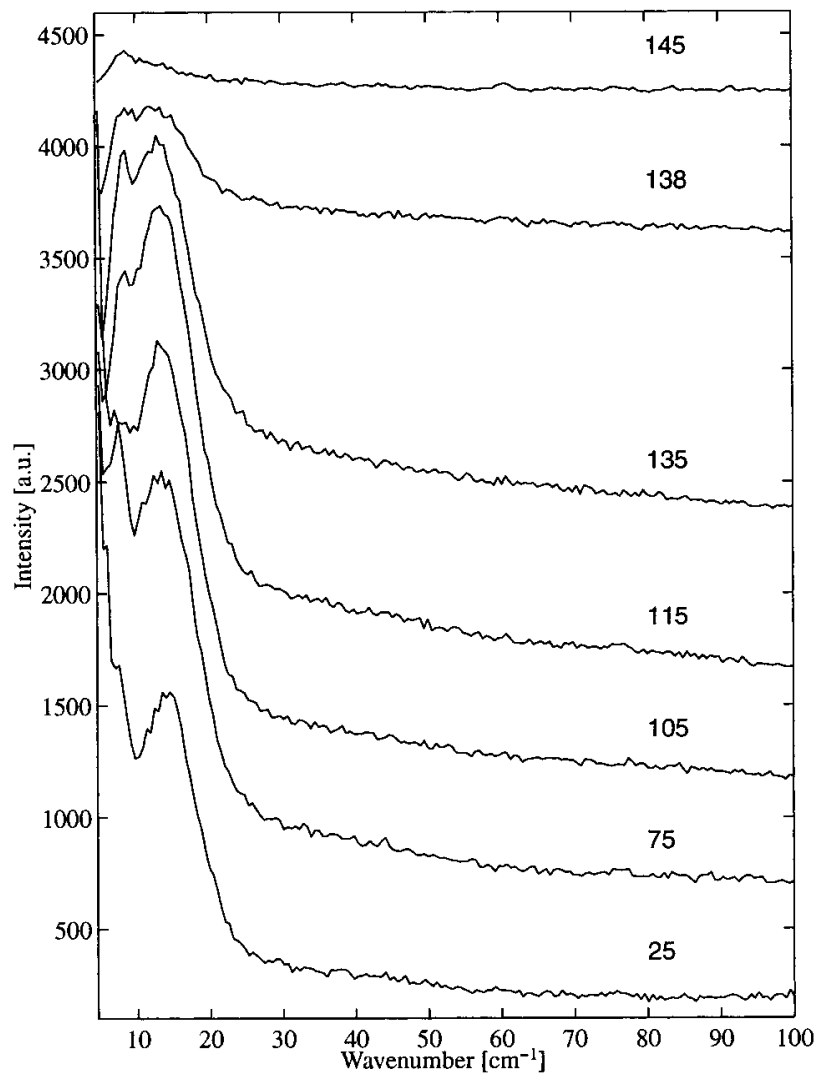

Figure 8. 2-D plot of the longitudinal acoustic (LA) Raman mode obtained during a heating scan from 50 to $145^{\circ} \mathrm{C}$ at 5 ${ }^{\circ} \mathrm{C} / \mathrm{min}$ of an annealed solution-crystallized film. The temperatures are plotted in the figure.

crystalline core of the anneal ed solution-crystall lized film does not vary with temperature. Secondly, the LA Raman mode in the solution-crystallized film is not influenced by the temperature. Thirdly, close to the melting temperature, $138{ }^{\circ} \mathrm{C}$, a drop in the intensity with broadening of the peak to higher frequencies (i.e., decrease in thickness of the crystalline core) highlights the melting behavior of the crystalline core. The shift to lower angles in the SAXS just before the melting temperature, shown as region CD in Figure 5, can therefore be associated with the melting of the crystalline core, i.e., the lamellar surface, rather than interchain diffusion between the adjacent lamellae. Taking into consideration the conclusions drawn from Figure 8, we will analyze our experimental observations made on the unannealed solution-crystallized film during heating, as shown in Figure 9 and discussed below.

Chain Rearrangement in the Crystalline Core as a Function of Temperature. In Figure $9 a$, a shift of the LA Raman mode to lower frequencies is observed with heating at a rate of $1{ }^{\circ} \mathrm{C} / \mathrm{min}$. The absence of a peak shift as a function of temperature in the annealed solution-crystallized film (Figure 8) indicates that the shift in LA Raman peak in Figure 9 is solely due to chain rearrangement. The three-dimensional plot in Figure 9a shows a sharp peak at $26.7 \mathrm{~cm}^{-1}$ at the start of the experiment, which broadens and moves to lower frequencies above the threshold temperature of $110^{\circ} \mathrm{C}$. The peak shifts gradually from 26.7 to $13.2 \mathrm{~cm}^{-1}$ with increasing temperature. The maximum shift to 13.2 $\mathrm{cm}^{-1}$ is observed at approximately $130^{\circ} \mathrm{C}$, where the peak strengthens in intensity. Figure $9 \mathrm{~b}$ is a set of collected LA Raman modes at different temperatures displayed in two dimensions to show this effect more a

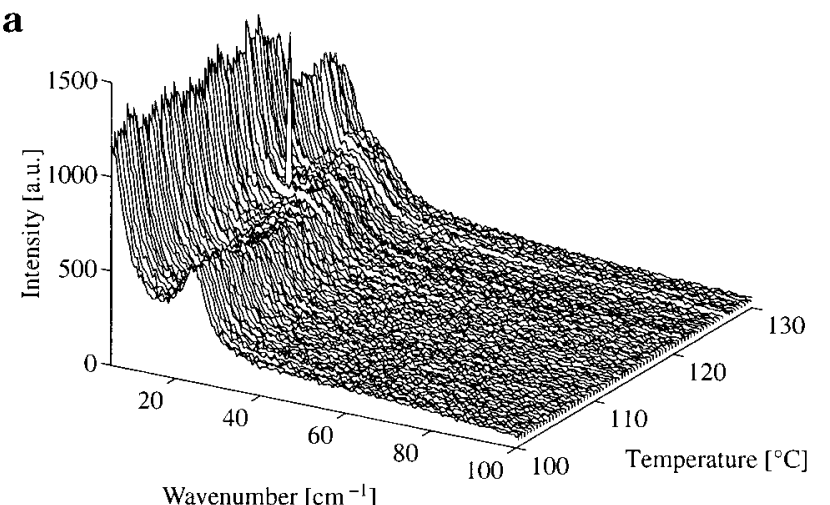

b
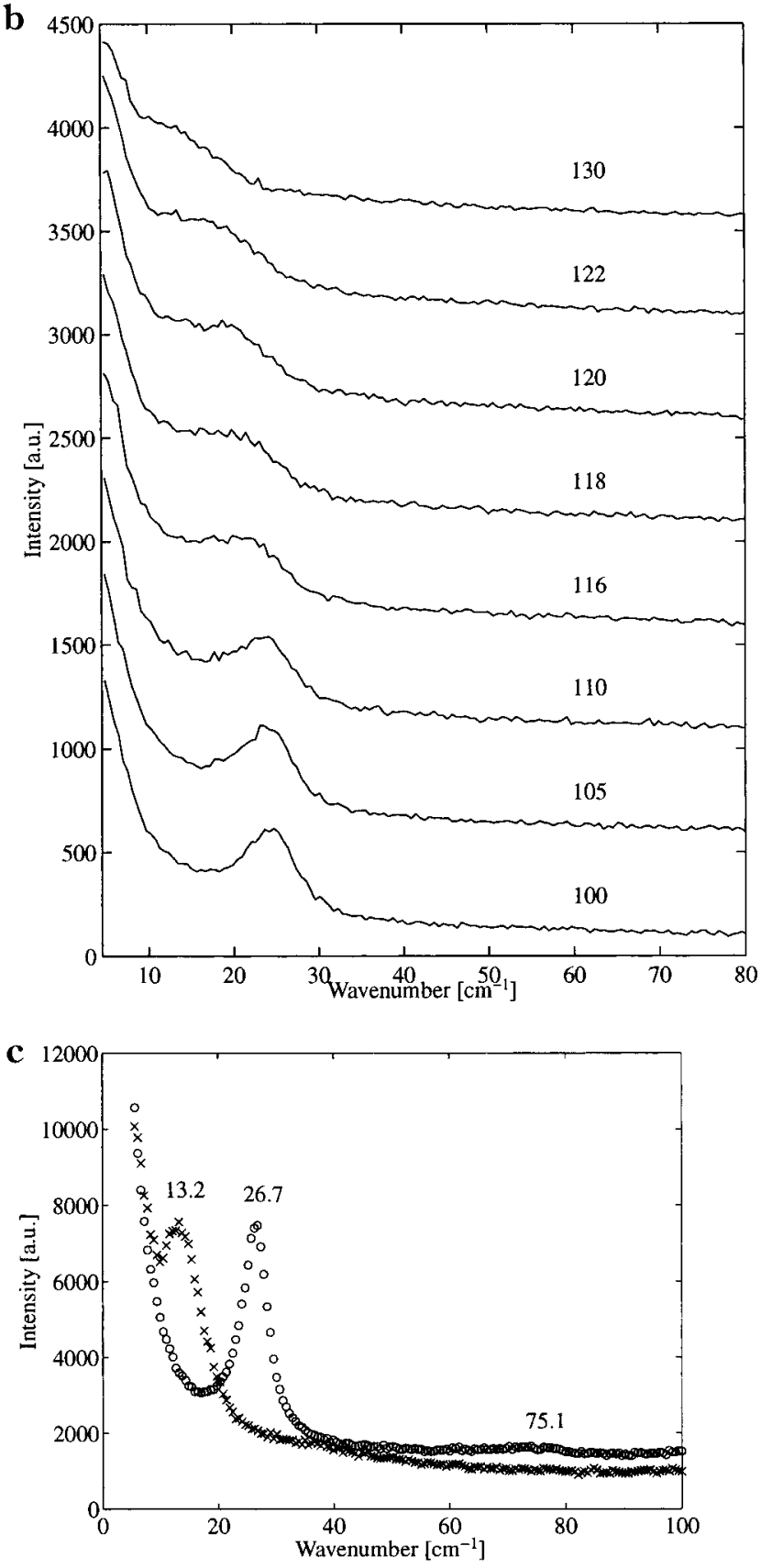

Figure 9. (a) 3-D plot of the LA Raman mode from a heating scan of the solution-crystallized film from 100 to $130^{\circ} \mathrm{C}$ at 1 ${ }^{\circ} \mathrm{C} / \mathrm{min}$. (b) 2-D plot of representative temperatures during this heating scan. (c) Comparison of the LA mode measured at room temperature between an unannealed and annealed film: (O) unannealed film; $(x)$ annealed film. 
clearly. On cooling, from $130^{\circ} \mathrm{C}$ to room temperature, the band at $13.2 \mathrm{~cm}^{-1}$ strengthens in intensity and becomes more distinct, as shown in Figure 9c, which also shows a comparison with the unanneal ed film at room temperature. From the set of experiments shown in Figures 8 and 9, it is clear that the crystalline core increases in thickness above the threshold temperature of $110{ }^{\circ} \mathrm{C}$ to twice the initial value. The continuous shift in the LA Raman peak to lower frequencies cannot be associated with the melting of alternate lamellae or the crystalline core.

Recently, Valisa et al. published their results on the melting of melt-crystallized high-density polyethylene. ${ }^{31}$ These results were based on studies performed in-situ by Raman spectroscopy in the LA mode region. While recording spectra for $120 \mathrm{~s}$ during heating at the rate of $1{ }^{\circ} \mathrm{C} / \mathrm{min}$, Valisa et al. found that in melt-crystallized polyethylene the LA Raman mode frequency increases to higher values before it decreases. These results point to the premelting of the crystalline core followed by a complex recrystallization process involved during the lamellar thickening. In contrast to these findings, our experiments on the solution-crystallized UHMW-PE film were performed with a recording time of only $12 \mathrm{~s}$ per spectrum using the same heating rate and no shift in the peak position to higher frequencies was seen (Figure 9a). Only a continuous shift in the LA Raman peak to lower frequencies was observed. Thus, our findings rule out the possibility of a melting and recrystallization process during lamellar thickening. The continuous shift in the LA Raman peak to lower frequencies clearly points to the fact that the increase in lamellar thickness is due to the interchain diffusion between the adjacent lamellae. The difference in the studies performed by Valisa et al. and by us is related to the sample preparation; this is due to the ingrained morphology in the arrangement of lamellae. In the melt-crystallized polyethylene, the lamellae are arranged in spherulites and the lamellar thickness is widely distributed, whereas in the solution-crystal lized film the lamellae are well stacked like a pack of cards, and a sharp distribution in lamellar thickness exists. The chain sliding diffusion leading to lamellar thickening cannot be realized within the lamellae arranged in the spherulite, while on the other hand the regular stacking of crystals in the solution-crystallized film facilitates the process of chain sliding between the adjacent lamellae.

The SAXS, TEM, and LA Raman spectroscopy techniques are used to follow the chain rearrangement in the bulk material. When lamellae are not regularly stacked, which would be the situation in spherulitic growth, thickening in the majority of the bulk would occur via a melting and recrystallization process. The thickening mechanism via mutual chain rearrangement (or chain sliding diffusion) in spherulites can occur in specific regions of the bulk, where two or more crystals are regularly stacked. On the other hand, the regular morphology in the bulk material of the solution-crystallized films allows the mutual chain rearrangement between the adjacent lamellae during thickening to be followed by these techniques. Thus, we are dealing here with secondary thickening, ${ }^{32}$ which is perfecting the crystals, viz. the reduction of the basal surface area of the lamellae per unit mass of already crystallized material.

During lamellar thickening the broadening of the LA Raman peak together with a drop in the overall inte- grated intensity can be explained by the mutual chain rearrangement between the neighboring crystals. The enhanced chain mobility experienced during the chain rearrangement in the crystalline core will cause a drop in the elastic moduli along the chain direction. This leads to the total drop in the integrated intensity of the LA Raman peak. The continuous chain diffusion between the adjacent crystals results in an increase in the effective length of the chain segment in the crystalline core, which will mainly result into the continuous shift in the LA Raman peak to lower frequencies. The thickening process, as observed by SAXS measure ments, occurs over a wide temperature region of 110$123^{\circ} \mathrm{C}$ (region BC in Figure 5). Therefore, within this temperature region the LA Raman peak would be rather broad and will be noticed as a continuous shift to lower frequencies. The peak position at $13.2 \mathrm{~cm}^{-1}$ of the broad LA Raman peak is noticed above $123^{\circ} \mathrm{C}$, which intensifies and becomes sharp on cooling to room temperature (Figure 9c). During the chain rearrangement, a drop in the crystallinity will be also anticipated, which should be an explanation for the dip in crystallinity as measured by WAXS by other authors. ${ }^{33,34}$

The quantum increase in lamellar thickness has been observed in sharp fractionated paraffins, 35 low molecular weight poly(ethylene oxide), ${ }^{36,37}$ block copolymers (poly(ethylene oxide) and polystyrene), ${ }^{38}$ and single crystals of nylon $6,6 .{ }^{27}$ The quantum increase in the thickening during the very initial stages of crystallization in the sharp fractionated polyethylene from the melt ${ }^{39}$ has also been reported. One of the common morphological features, wherever the quantum increase in lamellar thickness is observed during annealing or heating bel ow the melting temperature, is that the bulk of the material contains regularly stacked lamellae. ${ }^{35,36,37}$ A comparison between paraffins and UHMWPE shows that the quantum increase in the thickening process is independent of the molecular weight. This suggests that the mutual chain rearrangement between the adjacent crystals is a co-operative phenomenon where certain localized chain segments are involved rather than the whole chain. Dislocations thus generated during thickening tend to move out of the crystal lattice to minimize the energy. A doubling scheme for the chain rearrangement between the adjacent crystals leading to doubling of the fold length has been proposed by Dreyfuss and Keller for nylon 6,627 and thereafter proposed to occur by Barham and Keller ${ }^{39}$ for the case of isothermal crystallization of polyethylene, i.e., primary thickening. With the help of neutron scattering, Sadler has investigated the dimensions of individual molecules and changes in relative positions of different mol ecules during the annealing of solution-grown single crystals of polyethylene. ${ }^{40}$ On following the chain trajectory of the deuterated molecule, it was found that on annealing at $123^{\circ} \mathrm{C}$ or lower, the dimensions al ong the normal to the crystal lamellae increase in line with the lamellar thickness. During the thickening process the dimensions in the plane of crystallites were found to remain constant.

Taking the literature and our own results into account, the following model is proposed for the quantum increase in the lamellar thickness. The mechanism of the doubling process will be explained in view of the experimental details.

Figure 10a shows a schematic drawing of the regularly stacked lamellae as interpreted from the transmission electron micrograph of the solution-crystallized film 


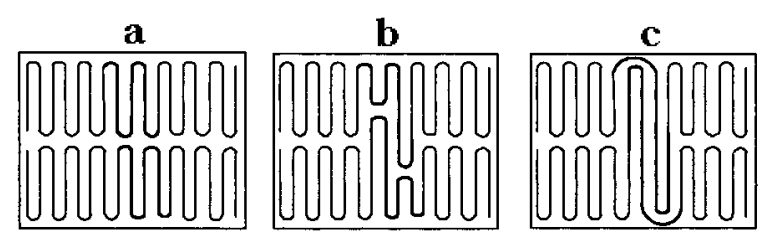

Figure 10. Schematic model to explain the doubling phe nomenon in the regularly stacked adjacent lamellae. The bold line represents the test chain.

(Figure 3b). Once the film is heated above the $\alpha$-relaxation temperature, the thermodynamic driving force for lamellar thickening, necessary to minimize the surface free energy, will cause the chains to slide within the lamellae. The sliding chain within onelamella will push the chain in the adjacent lamella, as shown schematically by the bold line, representing the test chain, in Figure 10b. For the sake of simplicity we have restricted ourselves to the selected region of the crystals. It has to be noted that the chains will slide between the adjacent crystals along the crystal lattice. Defects, associated with the fold surface, that are introduced within the crystal lattice during chain sliding will be removed once the crystal thickness has increased to twice the initial thickness. This is shown in Figure 10c. The thickening process will be co-operative within the whole crystal and can be observed as a drop in the modulus or crystallinity of the bulk. ${ }^{41}$

From our SAXS studies it is evident that between 110 and $120{ }^{\circ} \mathrm{C}$, mainly two populations of the crystals possessing a lamellar thickness of 12 and $24 \mathrm{~nm}$, respectively, exist. With increasing temperature (between 110 and $120^{\circ} \mathrm{C}$ ), while the population of $12 \mathrm{~nm}$ thick crystals decreases, the population of $24 \mathrm{~nm}$ crystals increases simultaneously. This indicates that within this temperature regi on, the chains are continuously reorganizing via thickening of the crystalline core. The SAXS technique, measuring the electron density difference between the amorphous and crystalline material, is not suitable for recording the intermediate stages of the thickening process. The continuous chain reorganization within the sample (bulk) is reflected in the broadening of the LA Raman modes, which will provide information on the intermediate stages of thickening between the doubling process, as shown schematically in Figure 10b. However, because of statistically varying distribution of defects (e.g., kinks) during the chain reorganization, a range of "moduli" could be expected that may also lead to a spread in LA Raman modes-at least such a possibility should not be ignored. Thus, in the present study, we have refrained from providing quantitative values of the thickening rate. From the model, Figure 10b,c, it is evident that the thickening process will be observed as a quantum increase of the SAXS peak to lower angles and a shift (initially rather broad) of the LA Raman mode to lower frequencies.

From Figure 10c, it is evident that once the lamellae have doubled to twice the initial value, chains get mutually entangl ed at the surface and further thickening via mutual chain rearrangement between the adjacent crystals cannot occur. A further increase in lamellar thickness, which is logarithmic with time, should occur via melting and a recrystallization process. In this respect, our model is rather different than the one proposed by Keller and co-workers, 27,39 in which thickening can occur in quantum jumps, not only doubling but also up to quadrupling.

Similar observations were made by Zhu et al. 42 in solution-crystallized UHMW-PE films using WAXS and infrared spectroscopy under static conditions. The authors concluded from their experimental observations that the increase in the lamellar thickness along the c-axis to nearly twice the initial value occurs via chain sliding. During thickening, the crystal dimension along the b-axis increases, while the dimension along the $a$-axis remains constant. The increase along the b-axis suggested that the chain sliding along the c-axis is feasible, because of the expansion along the 020 sectors of the crystal. The experimental methods used by the authors showed a gradual increase in the lamellar thickness along the c-axis rather than the quantum jump noticed in our experiments.

\section{Conclusions}

From the above set of experiments the following conclusions could be drawn:

In the regularly stacked pol yethylene single crystals, thickening occurs during annealing via a mutual chain rearrangement between the adjacent crystals, which leads (ultimately) to a quantum increase, i.e., doubling, of the lamellar thickness. The quantum increase in the lamellar thickness can be explained by our proposed model.

After the doubling process has been completed, further thickening via mutual chain rearrangement is hindered due to the fact that chains at the surface get entangled and, moreover, the regular stacking of lamelIar crystals is lost. Further thickening of the doubled lamellar crystals involves a process of surface melting ${ }^{28}$ or melting and recrystallization. ${ }^{29}$

The rate of increase in the lamellar thickness, ultimately leading to the quantum increase, will be dependent on the annealing temperature; i.e., at the higher temperatures, the doubling process will be faster.

The kinetics of the doubling process is independent of the molecular weight and can be monitored by lowfrequency Raman spectroscopy involving the intermediate stages.

The observed results fit with past results and extend the past body of experience on chain refolding by doubling and coalescence of adjacent crystals as stated in the text with the major difference that thickening beyond doubling could not be observed.

Acknowledgment. The authors wish to thank Prof. A. Keller (Bristol) for numerous stimulating discussions. The authors are grateful for the availability of the facilities at Station 8.2 of the Synchrotron Radiation Source (SRS), Daresbury, U.K., and at Beamline ID11/BL-2 of the European Synchrotron Radiation Facility (ESRF), Grenoble, France. Further, the authors are thankful for the experimental facilities available at Dilor, Lille, France, for the Raman measurements.

\section{References and Notes}

(1) De Gennes, P. G. Scaling Concepts in Polymer Physics; Cornell University Press: Ithaca, NY, 1978.

(2) De Gennes, P. G. J . Chem. Phys. 1971, 55, 572.

(3) Doi, M.; Edwards, S. F. J . Chem. Faraday Trans. 1978, 2, 74, 1789, 1802, 1818.

(4) Bastiaansen, C. W. M.; Meijer, H. E. H.; Lemstra, P. J Polymer 1990, 31, 1435.

(5) Bastiaansen, C. W. M. Ph.D. Thesis; Eindhoven University of Technology, 1991.

(6) Ferry J. D. Viscoelastic Properties of Polymers, 2nd ed.; Wiley: New York, 1970

(7) Lemstra, P.J .; van Aerle, N. A. M. J .; Bastiaansen, C. W. M. Polym. J . 1987, 85, 19.

(8) Barham, P. J .; Sadler, D. M. Polymer 1991, 32, 387. 
(9) Xue, X.-Q.; Tervoort, T. A.; Rastogi, S.; Lemstra, P. J . Submitted for publication to Macromolecules.

(10) Kim, I.; Krimm, S. Macromolecules 1996, 29, 7186.

(11) Bras, W.; Derbyshire, G. E.; Ryan, A. J .; Mant, G. R.; Felton, A.; Lewis, R. A.; Hall, C. J .; Greaves, G. N. Nucl. Instrum. Methods Phys. Rev. A 1993, A326, 587.

(12) Schaufele, R. F.; Schimanouchi, T. J . Chem. Phys. 1967, 47, 3605.

(13) Montezinos, D.; Wells, B. G.; Burns, J . L. J . Polym. Sci., Polym. Lett. Ed. 1985, 23, 421.

(14) Vonk, C. G. In Small AngleX-ray Scattering, 2nd ed.; Glatter, O., Kratky, O., Eds.; Academic Press: London, 1982.

(15) Fraser, G. V.; Keller, A.; Pope, D. P. Polym. Lett. Ed. 1975, $13,341$.

(16) Folkes, M. J .; Keller, A.; Stejny, J .; Goggin, P. L.; Fraser, G. V.; Hendra, P. J . Colloid Polym. Sci. 1975, 253, 354.

(17) Fraser, G. V.; Hendra, P. J .; Willis, H. A.; Cudby, M. E. A. J . Mater. Sci. 1974, 9, 1270 .

(18) Fraser, G. V. Indian J. Pure Appl. Phys. 1978, 16, 344; Polymer 1978, 19, 857.

(19) Dlugosz, J .; Fraser, G. V.; Grubb, D.; Keller, A.; Odell, J . A.; Goggin, P. L. Polymer 1976, 17, 471.

(20) Aerts, L.; Kunz, M.; Berghmans, H.; Koningsveld, R. Makromol. Chem. 1993, 194, 2697.

(21) Kunz, M.; Drechsler, M.; Moller, M. Polymer 1995, 36, 1331.

(22) Keller, A. Faraday Discuss. 1996, 101, 1.

(23) Smith, P.; Lemstra P.J .; Pijpers, J . P. L.; Kiel, A. M. Colloid Polym. Sci. 1981, 259, 1070.

(24) Peticolas, W. H.; Hibler, G. W.; Lippert, W. L.; Peterlin, L.; Olf, A. Appl. Phys. Lett. 1971, 18, 87.

(25) Strobl, G. R.; Eckel, R. J . Polym. Sci. 1976, A2 14, 913.

(26) Hsu, S. L.; Krimm, S.; Krause, S.; Yeh, G. S. Y. Polym. Lett. 1976, 14, 195.
(27) Dreyfuss, P.; Keller, A. J . Macromol. Sci., Phys. 1970, B4 (4), 811.

(28) Fischer, E. W. Pure Appl. Chem. 1972, 31, 113.

(29) Mandelkern, L. Macromolecules 1969, 2, 644.

(30) Cho, M. H.; Kyu, T.; Lin, J. S.; Saijo, K.; Hashimoto, T. Polymer 1992, 33, 4152.

(31) Valisa, P.; Villers, D.; Dosiere, M. Proceedings of the $15^{\text {th }}$ International Conferenceon Raman Spectroscopy, Pittsburgh, PA, August 11-16, 1996; Vol. B, p 39.

(32) Hikosaka, M.; Rastogi, S.; Keller, A.; Kawabata, H. J. Macrmol. Sci., Phys. 1992, B31 (1), 87.

(33) Kawaguchi, A.; Ichida, T.; Murakami, S.; Katayama, K. Colloid Polym. Sci. 1984, 262, 597.

(34) Kyu, T.; Fujita, K.; Cho, M. H.; Kikutani, T.; Lin, J. S. Macromol ecules 1989, 22, 2238.

(35) Ungar, G.; Stejny, J .; Keller, A.; Bidd, I.; Whiting, I. C. Science 1985, 229, 386.

(36) Kovacs, A. J .; Straupe, C. Faraday Discuss. Chem. Soc. 1979, 68, 225.

(37) Cheng, S. Z. D.; Chen, J .J . Polym. Sci., Part B: Polym. Phys. 1991, 29, 311.

(38) Ryan, A. J .; et al. Manuscript in preparation.

(39) Barham, P. J .; Keller, A. J . Polym. Sci., Part B: Polym. Phys. 1989, 27, 1029.

(40) Sadler, D. M. Polym. Commun. 1985, 26, 204.

(41) Our unpublished results.

(42) Zhu, Q. R.; Hong, K. L.; J i, L. Q.; Qi, R. R.; Zhou, G. E.; Song, M. S.; Wong, Y. W. J . Polym. Sci., Part B: Polym. Phys. 1995, 33, 739.

MA9705190 